\title{
Engineering as a tool for improving human habitat
}

\author{
Priti Parikh*
}

Department of Engineering, Centre for Sustainable Development and Newnham College,

Trumpington Street,

Cambridge CB2 1PZ, UK

E-mail: pp280@cam.ac.uk

*Corresponding author

\author{
Allan McRobie \\ Department of Engineering, \\ Cambridge University, \\ Trumpington Street, \\ Cambridge CB21PZ, UK \\ E-mail:fam@eng.cam.ac.uk
}

\begin{abstract}
The conventional approaches to poverty alleviation in the slums entail a cocktail of interventions in health, education, governance and physical improvements, often stretching the scarce resources far and thin. Driven by the 'poverty' mindset, physical measures such as minimal paving, public water posts and community latrines actually brand the slums apart instead of assimilating them into the urban infrastructure fabric. The concept of Slum Networking proposes comprehensive water and environmental sanitation infrastructure as the central and catalytic leverage for holistic development. At costs less than the conventional 'slum' solutions, it tries to penetrate a high quality urban infrastructure net deeply into the slums to assimilate them into the city rather than lock them in as disadvantaged islands. Further, it transcends resource barriers and 'aid' through innovative partnerships and the latent resource mobilisation potential of the so-called 'poor'. This paper examines Slum Networking as implemented in Sanjaynagar in Ahmedabad, India and compares it with a similar settlement with no interventions in Ahmedabad. It assesses the knock-on impact of physical infrastructure on health, education and poverty. Finally, it evaluates the multiplier effect of physical infrastructure and the partnerships on the subsequent investments by the community in its own shelter and habitat.
\end{abstract}

Keywords: multiplier; poverty; sanitation; Slum Networking; water.

Reference to this paper should be made as follows: Parikh, P. and McRobie, A. (XXXX) 'Engineering as a tool for improving human habitat', Int. J. Environmental Policy and Decision Making, Vol. X, No. Y, pp.XXX-XXX.

Biographical notes: Priti Parikh studied Engineering in India, and has worked there as a Development Engineer, including slum improvement projects and as a Volunteer Engineer in the aftermath of the 2001 Gujarat earthquake. She is now a PhD research student focusing on water and environmental sanitation in slums in India and South Africa, having completed MPhil in Engineering for Sustainable Development at Cambridge University in 2005. 
Allan McRobie is a Reader in Engineering at Cambridge University. He Lectures on Water Engineering and Structures. He worked on water resources and other projects in Eastern Australia with consultants Sinclair Knight and Cameron McNamara in the 1980s.

\section{Introduction}

More than a billion people worldwide have no access to an improved water source, and 2.5 billion do not have access to improved sanitation (WB, 2004). Most of these 2.5 billion people without improved sanitation are among those hardest to reach: families living in remote rural areas and urban slums, families displaced by war and famine and families mired in the poverty-disease trap. Out of the 1.1 billion people with no access to improved water source, $42 \%$ live in Sub-Saharan Africa. Similarly, in South Asia, only $37 \%$ of the population has access to improved sanitation (UNICEF/WHO, 2004). The UNICEF/WHO monitoring report also acknowledges that without a sharp acceleration in the rate of progress of sanitation, the world will miss half a billion people (UNICEF/WHO, 2004).

There are inequities in service provisions across and within countries either in the form of the rich-poor or urban-rural divide (Parikh, 2006). The poor often consume fewer infrastructure services and pay higher prices. The price subsidies reach the rich but not the poor who are actually engines of growth and contribute significantly to the economy in the form of market labour (Parikh, 2006). This is partly due to lack of access and partly due to inappropriate allocation of services by the government.

The conventional approaches to poverty alleviation in the slums entail a cocktail of interventions in health, education, governance and physical improvements, often stretching the scarce resources far and thin. Driven by the 'poverty' mindset, physical measures such as minimal paving, public water posts and community latrines actually brand the slums apart instead of assimilating them into the urban infrastructure fabric. This paper will examine the impacts of Slum Networking, a solution tried and tested in India.

\section{Slum Networking}

The concept of Slum Networking not only offers technical solutions for services provisions, but also looks at resources generation and partnerships for implementation. This concept was conceived and developed by Mr. Himanshu Parikh, a consultant engineer based in Ahmedabad (Diacon, 1997). Slum Networking is an innovative concept which exploits the linkages between the slums, natural drainage paths which influence the urban infrastructure and the environmental fabric of the city. Thus slums, instead of being resource draining liabilities as in the conventional developmental approach, actually become opportunities of a quantum change in the infrastructure levels and environmental quality of the city (Parikh, 1999).

The concept of Slum Networking does not accept that the constraints, both physical and financial, are insuperable. It is underpinned by a fundamental belief that slums need not exist in India and this massive transformation can be achieved in a short time span (Parikh, 1995). 
Slum Networking was first implemented in Indore to directly benefit 450,000 persons (Diacon, 1997). Its weakness, however, was that it was funded by grant from the British government (Parikh, 1995). As a first step to get away from aid, a project was taken up in Ramdevnagar slum in Baroda city in which the resources were mobilised locally from the community and Municipal Corporation partnership, though UNICEF provided some leverage funds. In the final evolution to self-sufficiency, a pilot project in Sanjaynagar slum in Ahmedabad city totally dispensed with external aid, replaced by an equal partnership between the community, Ahmedabad Municipal Corporation and Arvind Mills Limited, a local textile group. By December 2005, the project was up-scaled by Ahmedabad Municipal Corporation to 41 slums, covering 8703 families and making a significant difference to the lives of 43,515 people (AMC, 2005). However, the private investor, Arvind Mills did not join the next phase and the services of Himanshu Parikh were also dispensed with (Tripathi, 1999). The project was renamed as Parivartan (change).

\section{Data collection}

This paper focuses on Sanjaynagar slum, Ahmedabad, where holistic physical infrastructure under the Slum Networking Project was implemented in 1997. The special features of this case study are the involvement of the corporate sector, provision of tenure rights and community ownership. For comparative evaluation, the second case study chosen was 'Lakshman Zaduwala ni Chali' settlement, which is located in Khokhra ward of the city and will hereafter be referred to as Khokhra. The primary difference between the two case studies is the provision of physical infrastructure in Sanjaynagar as against the lack of adequate facilities in Khokhra.

For each case study, 20 houses were interviewed. This represents $11 \%$ sampling (181 households) in Sanjaynagar and 14.9\% sampling (134 households) in Khokhra. Twenty households, although statistically acceptable, is not a large sample size and this research also draws on information from secondary sources like 'A profile of Sanjaynagar' (SAATH, 1995) and the book Alliance for Change (Tripathi, 1998).

Detailed questionnaires were used to collect a wide range of data from the households on family background, employment, incomes, infrastructure provisions, education, health and tenure. The interviews were conducted in the local language, Gujarati, in Sanjaynagar and in Hindi at Khokhra. Group discussions were also conducted in the year 2005 before commencing the surveys.

The questionnaires for Sanjaynagar and Khokhra were slightly different in one aspect. As Slum Networking was implemented in Sanjaynagar, the questionnaire also covered the difference before and after the provision of services. In Khokhra, as there are no facilities, questions related to their impact were not relevant. Non-parametric tests like the Sign Test, the Wilcoxon Test and the Mann Whitney U-Test were used for analysing the household data (Siegel, 1956).

\section{Impacts on health}

The impacts on health have been estimated from the medical expenses and work days lost due to illness information gathered during the interviews. A community survey carried out jointly by the NGO SAATH and by SHARDA TRUST has also been used. 
This survey covered 131 households of Sanjaynagar in 1995 and 100 houses in 1999 with 100 common households constituting $73 \%$ of the total surveyed sample size (SHARDA Trust and SAATH, 1999).

The comparison of mean household monthly medical expenses in Figure 1 showed marked differences between preproject Sanjaynagar, post-project Sanjaynagar and Khokhra. The monthly medical expenses for Sanjaynagar have reduced to almost one-third of the preproject. Similarly, the current medical expenses in Khokhra are double than those in Sanjaynagar. The reduction in medical expenses means that the community has greater disposal resources for investments and savings.

Figure 1 Mean household monthly medical expenses (see online version for colours)

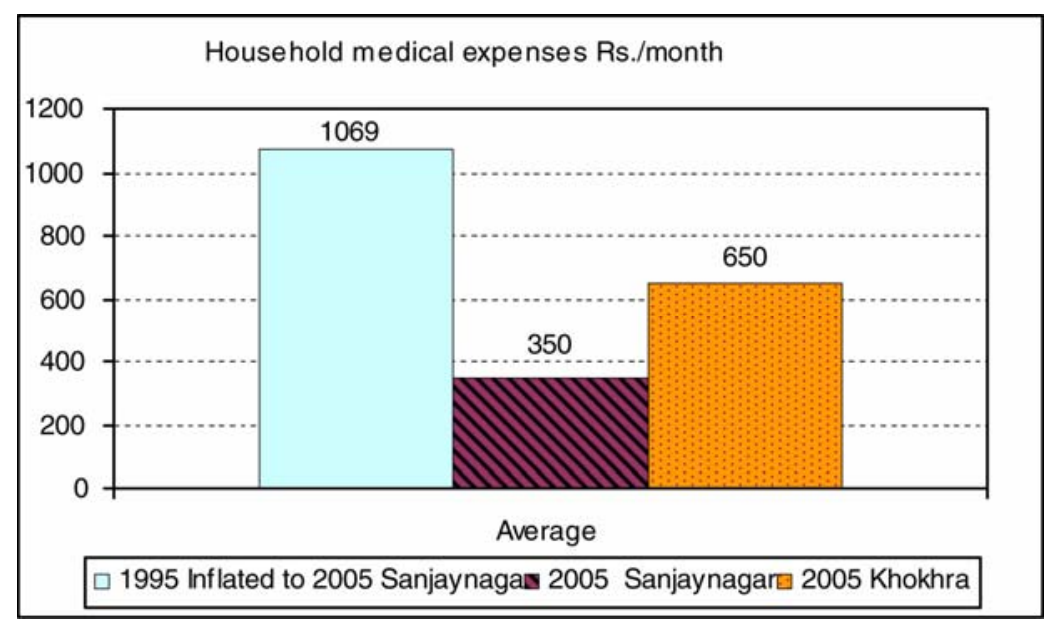

The comparison between the pre- and post-project scenario for Sanjaynagar shows clearly the number of work days lost to illness reducing significantly in Figure 2. The reduction in lost work days means that people can increase their incomes and invest more time in other meaningful activities like sending children to school, improving housing, etc.

Figure 2 Monthly work days lost due to illness (see online version for colours)

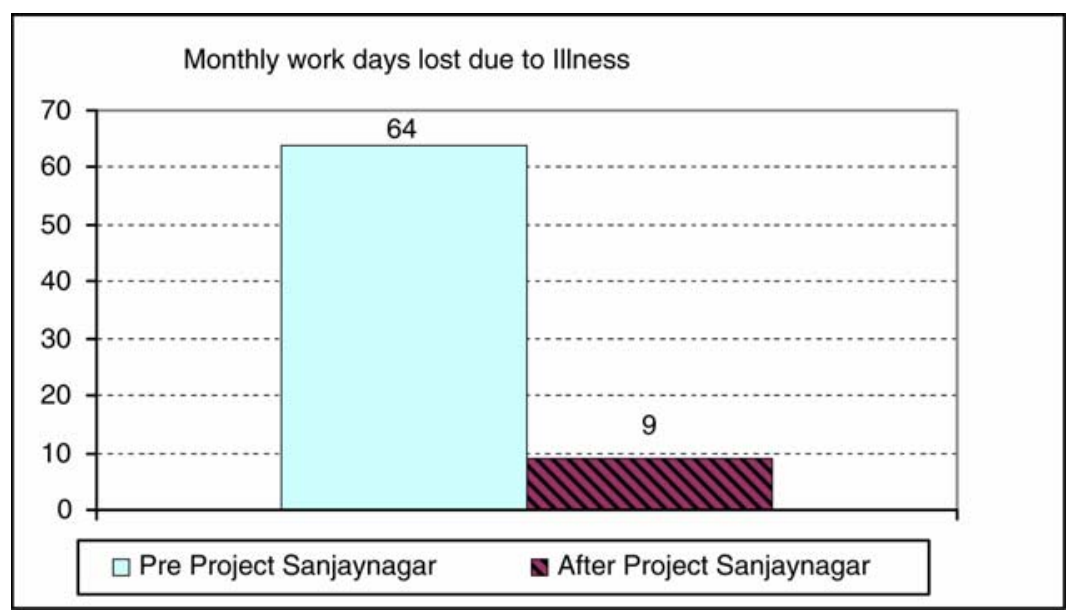


Most health programmes focus on infant mortality as this age group is particularly vulnerable to diseases like diarrhoea and malaria. Owing to reduced immunity, any major or prolonged illness can result in death. The infant mortality rate has reduced to a third in Sanjaynagar post-project implementation. This result also matches with secondary studies for Sanjaynagar (SHARDA Trust and SAATH, 1999).

There are clearly health improvements in Sanjaynagar after development, with results better than the current Khokhra situation. About $100 \%$ of the households surveyed in Sanjaynagar felt that the provision of facilities has led to health improvements. In order to cross check, a similar question was posed to the Khokhra residents about their perception of illnesses and the factors causing the illnesses (Figure 3). The Khokhra residents reported a high proportion of illnesses of recurring nature in their settlement. Dirt was perceived to be the main reason for the health problems (Figure 4). The next one was lack of facilities and then waste water outside house, mosquitoes, air pollution and no taps. All the causes are really related to infrastructure deficiencies. For instance, dirt outside houses signifies the lack of paving, storm drains and water logging. Similarly, mosquitoes breed in ponded water.

Figure 3 Perceived illness frequency in 20 houses, Khokhra (see online version for colours)

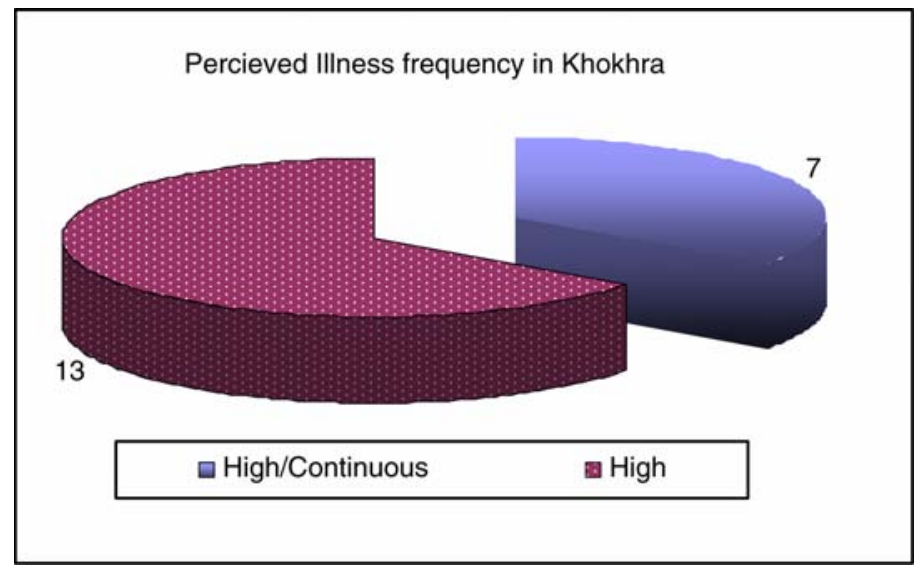

Figure 4 Health problem causes in 20 houses, Khokhra (see online version for colours)

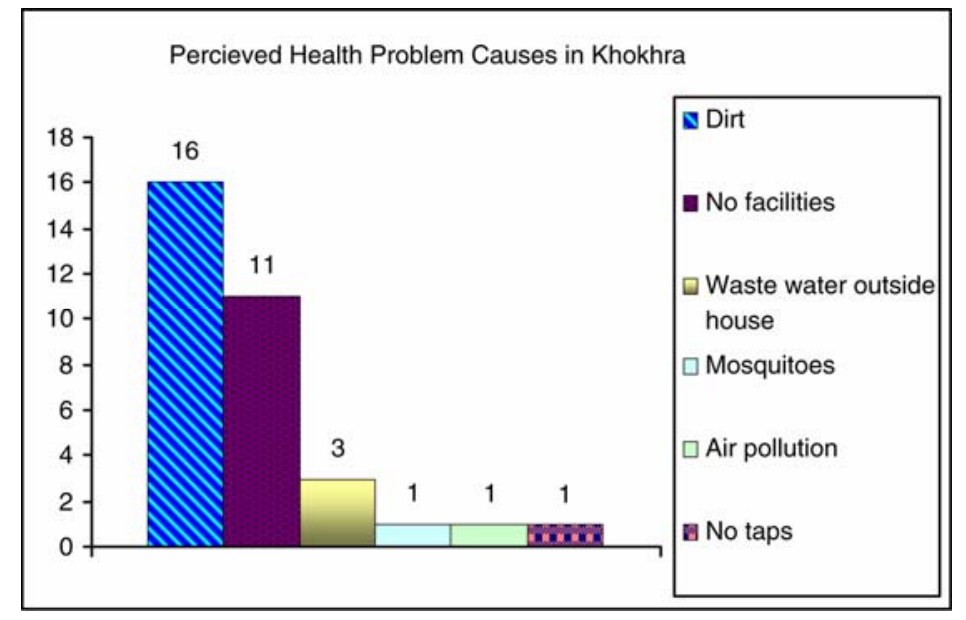


During the group discussions and household interviews, many other interesting observations were recorded. They are presented in the form of quotes as it is difficult to measure or quantify some of the benefits. For instance, a lot of women in Sanjaynagar have highlighted that they no longer have to carry buckets of water which, apart from saving time and labour, has reduced their back problems.

"Not having bath everyday creates body odour, due to perspiration. Also, bathing everyday makes my body feel furt (energetic). Previously I would feel sust (lethargic). Diseases do not come if you bath. Now I sweep and mop the floor of my house."(Source: Change After Alliance)

"Girls had to spend time disposing waste water from the house as boys wouldn't do this work. They can now wake up late and sleep more." (Source: Group Discussion, 2005)

\section{Impact on education}

The impact of education has been estimated both from attendance and the quality of education, based on the household interviews in Sanjaynagar and Khokhra. Information has also been drawn from community surveys (SnehPrayas, 2004) which look at the educational background of all children in Sanjaynagar.

Figure 5 shows a comparison of percentage of children attending schools in Sanjaynagar and Khokhra. The \% attendance is a ratio of number of children attending school divided by the number of school going age children. Children between the ages of 6 and 18 years are assumed to be school going age. On all counts, post-project Sanjaynagar shows a higher \% attendance. The Sanjaynagar figures also reflect the national trend of higher attendance rates of the male child, though it is worth noting that the percentage of female attendance has significantly increased post-project.

Figure 5 Percentage of children attending school (see online version for colours)

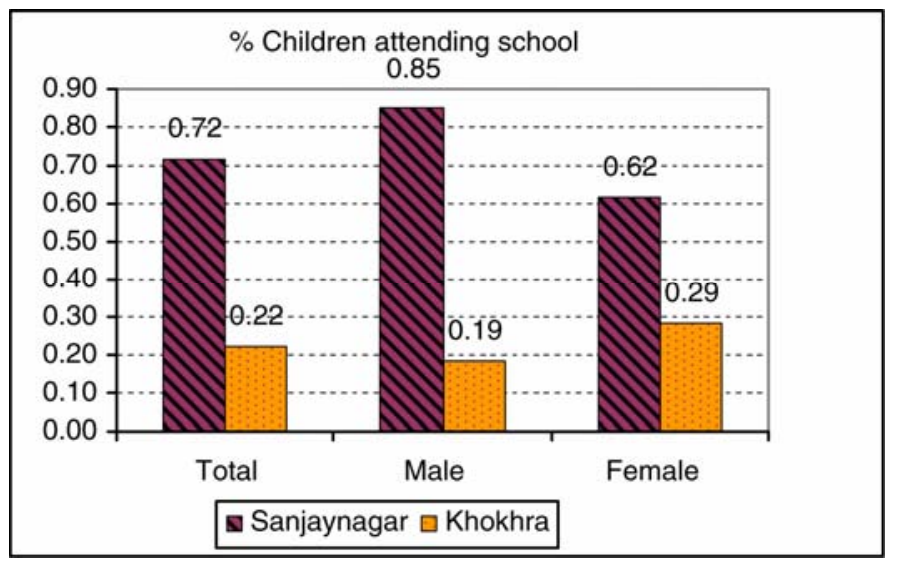

In India, municipal schools are run by the government. They do not charge fees to reach the children in the lower income strata. Private schools in India charge fees and cater to middle and high income groups, though they are not normally as exclusive as in the west. The group discussions and household interviews showed that in Sanjaynagar, private schooling was perceived as superior. 
Figure 6 shows a comparison of the number of children studying in private schools pre- and post-project in Sanjaynagar and also the current situation in Khokhra. In Khokhra, not a single child from the 20 households interviewed goes to a private school. A comparison of Sanjaynagar settlement shows an increase in the number of children attending private school, most significant being the private schooling for four female children. In order to send their children to private schools, the interviewed families had to incur an average expense of Rs. 3872 every year. This amount includes the term fees, monthly fees, cost of books and uniforms. The average annual expense on education is equivalent to $40-75 \%$ of monthly incomes.

Figure 6 Children attending private school (see online version for colours)

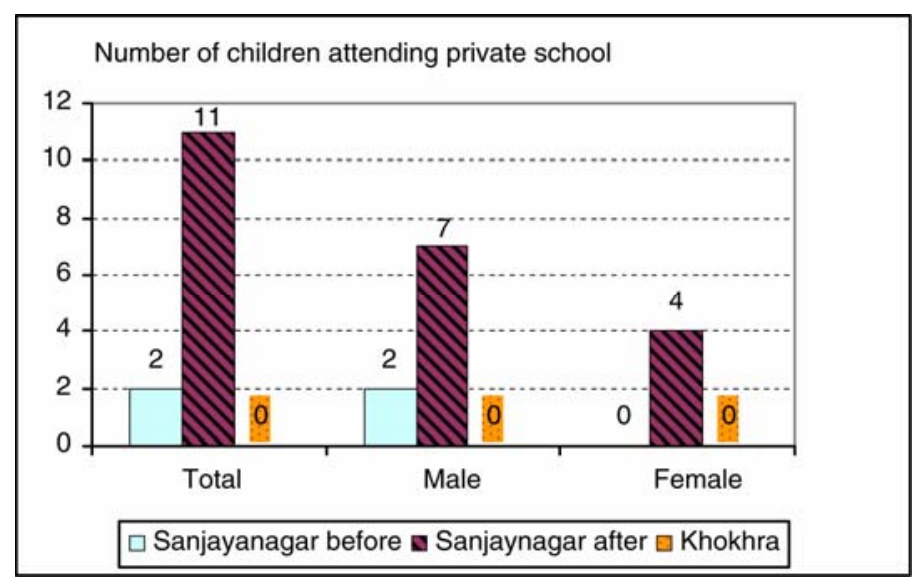

In contrast, the residents of Khokhra have not invested money for their children's education.

It is not just the expense, but the change in perception about education and the zeal to strive for high quality education which is more noticeable. The necessity of education is now entrenched in the mindset of Sanjaynagar residents whilst those in Khokhra feel that education is irrelevant as their children will work as labourers when they grow up.

Due to provisions of electricity and increasing incomes, people now have fans and lights to read and sit in the houses during day and night times. Education can be within and outside the classroom and television is an important medium. People's lives have been transformed in Sanjaynagar owing to television. Out of the 20 houses interviewed, only 3 houses do not have televisions, sharing with their neighbours instead. 10 out of the 17 families have colour televisions, those having black and white sets aspiring to change to colour. It is difficult to measure the change in lifestyle due to television. So, perhaps, the quotes would help.

"90\% or more houses have TV. We are now in the contact with world and know what is happening around us and we see the news. Ignorance is now reducing and TV shows like Discovery channel shows us things that we have never dreamt or seen before." (Source: Group Discussions, 2005)

"Young girls watch all the soaps carefully. They want to now wear nice clothes, cut their hair regularly, shampoo hair and use cosmetics. Expenses have now increased as girls are now influenced by advertisements in radio and TV. Everyone now knows about Fair and Lovely (a fairness cream) which is available for Rs. 5!" (Source: Group Discussions, 2005) 
All the respondents in Sanjaynagar perceived the infrastructure facilities to be the main cause of improvement in education. Similarly, when the counter question was posed to the residents of Khokhra, all the respondents highlighted that the lack of facilities was the cause of problems with education. These perceptions strongly support the linkage between facilities and education. Intangible changes like time saving because of facilities can lead to improvement in education.

\begin{abstract}
"Education is the foundation of life and can help us immensely. People think that computers will also come one day." (Source: Group Discussions, 2005)

"Municipal schools do not teach well. Children in private schools know ABCD and English from class 1 but children in municipal schools cannot even write their names in class 7. So we prefer to send our children to private school even though the fees are high.” (Source: Group Discussions, 2005)

"Children go to school now. Previously there was no time to send children to school. If the women go out of their houses to fetch water who will get the children ready to go to school?" (Source: Group Discussions, 2005)
\end{abstract}

\title{
6 Impact on income
}

In Sanjaynagar, an impression of increased spending was clear during the field work, as seen from lifestyle changes, investments in education, shelter upgradation and other spending.

However, as seen in Figure 7, the formal reported incomes appeared to belie this. Although reported incomes are much higher than the national slum averages, they were less than the preproject incomes obtained from secondary sources. The problem in comparing directly reported incomes with secondary data is that the community on the whole is very secretive and suspicious about income surveys. They under report their incomes and do not include informal cash transactions and subsidiary seasonal and irregular incomes.

Figure 7 Average monthly incomes, Sanjaynagar (see online version for colours)

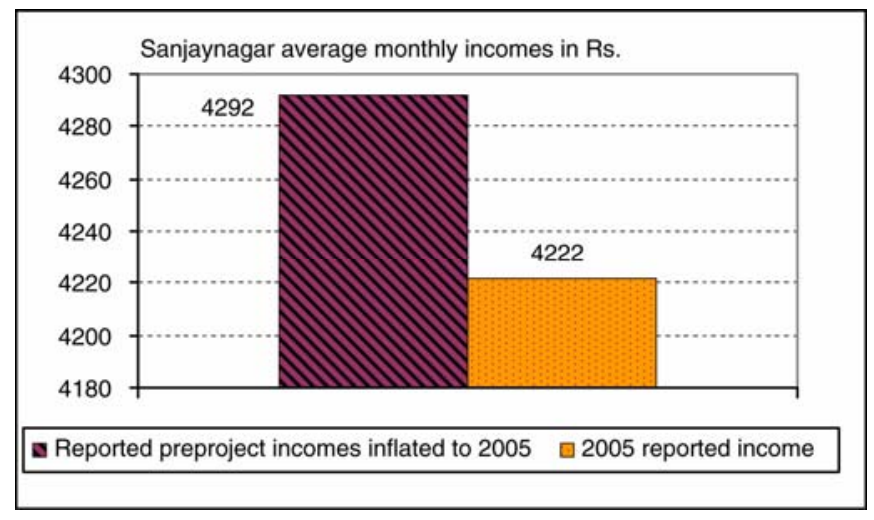

It was, therefore, decided to use the generally accepted survey tool of deriving incomes from the quantifiable expenditures. Comparisons were made between the reported expenditures for pre- and post-Sanjaynagar scenario and Khokhra and the estimated current monthly spending for Sanjaynagar. 
The current monthly spending of the families was estimated from the monthly medical expenses, education costs, bills, electricity charges, cable TV costs and investments in vehicles and housing. Food, grocery and clothes expenditure was estimated from the consumption pattern and the number of members in a family. As seen in Figure 8, expenditures showed very clearly that disposable incomes in Sanjaynagar have almost increased by $50 \%$ in real terms postproject and are almost double that of Khokhra. This is a remarkable increase.

Figure 8 Expenditure comparisons (see online version for colours)

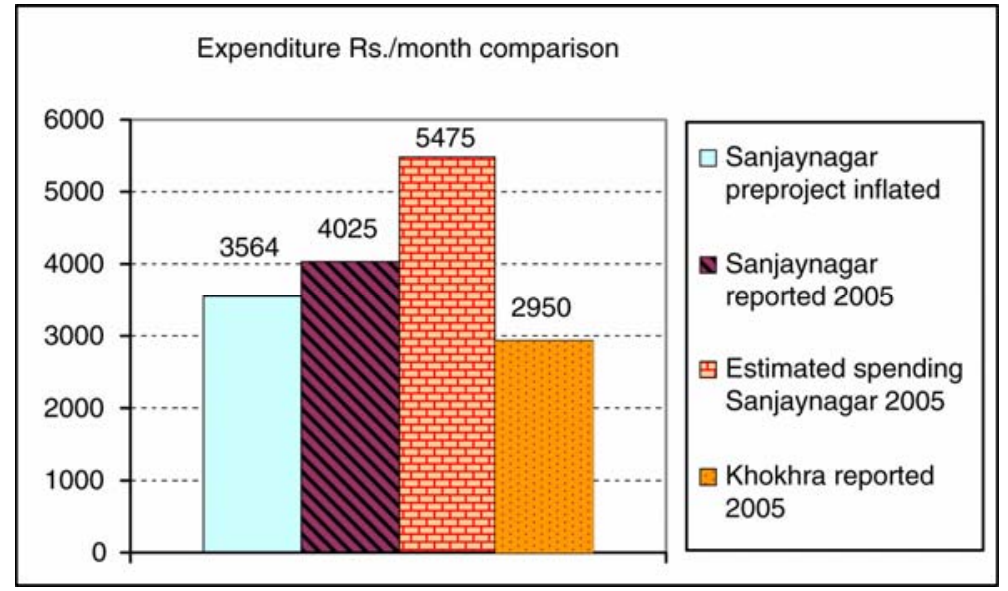

The reasons for this increase cannot be absolutely established by simple surveys and statistical analysis. As the only major intervention in Sanjaynagar was in the physical facilities, and also as corroborated in group discussions, infrastructure provisions appear to be the principal catalyst of poverty alleviation, perhaps underpinned by the associated security of tenure.

\section{$7 \quad$ Project costs and sharing}

The Sanjaynagar project was initiated with the principle objective of providing high quality infrastructure, not just by better technical solutions but also by factoring in the investments by business sector and, in particular, the community contributing as a partner instead of just a 'beneficiary'. The community agreed to pay one-third of the costs of physical works amounting to Rs. 2000 (£30) in 1997. Sceptics feared that the community would not manage this. The community managed to pay easily, but put forward conditions that the payment would be in instalments and that tenure security would be provided. Microcredits did help, though many families did not avail of this facility.

\section{Changes in housing stock}

There has been a dramatic transformation in the housing stock of Sanjaynagar. The residents themselves from loans, savings, extra labour or selling family jewellery 
have made the investments. The kutcha houses are now transformed into pucca brick houses with corrugated sheet roofs and tiled floors. Most families plan next to replace the roofs with concrete slabs. Even the furnishings and the cleanliness have improved.

The investments in house improvement by the community were recorded in the study. However, as these were carried out in stages with also the possibility of under or over reporting, the stated investments were cross checked and brought on par to present prices on the basis of built up area, type of construction and finishes and the prevailing construction costs in the area. The cost of toilet construction has been deducted uniformly as it was largely subsidised.

In addition, there have been substantial investments in goods like televisions, phones, refrigerators and vehicles. The term Housing \& Goods in Figure 9 represents the sum of total investments in housing and goods. The first bar shows that it is 8.2 times the initial investment in physical infrastructure. If the infrastructure costs are shared on partnership basis, the government investment drops to a third and the multiplier on the state investment alone increases to a massive 24.6 times!

Figure 9 Multipliers achieved on state investment (see online version for colours)

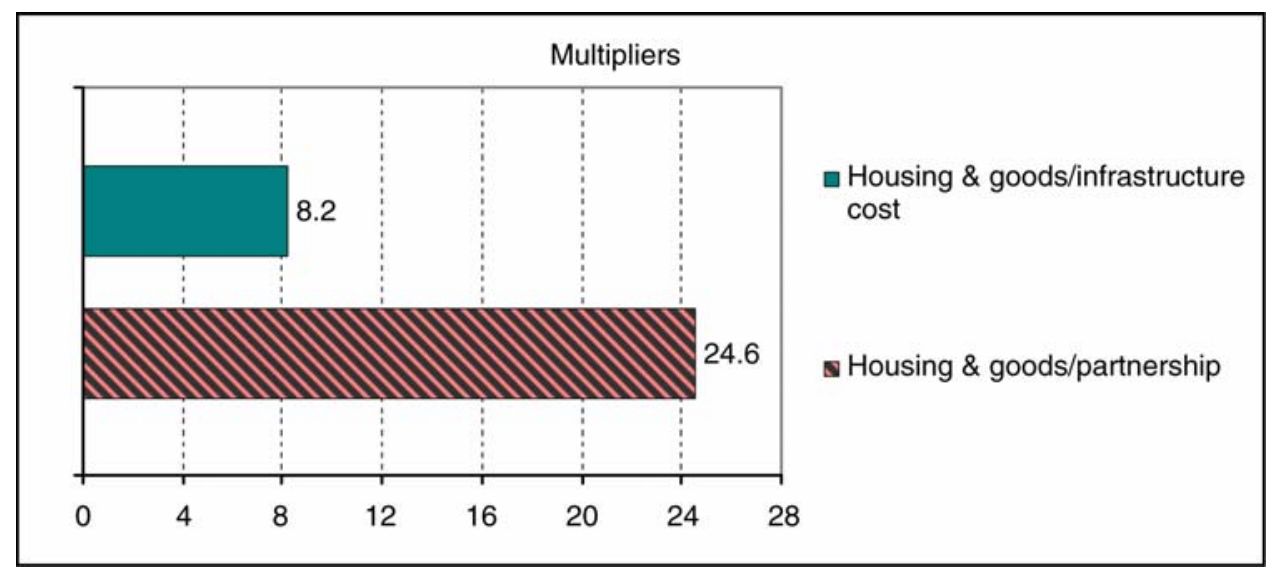

This is a crucial point for formulating habitat projects in countries, where government resources are scarce and the problems of poverty are widespread. Huge public investments have gone into housing whereas the same end results, probably on much larger scale, can be achieved through innovative approaches and partnerships with much smaller government contribution.

It is established that the community has made huge investments in upgrading of shelter, but it is equally important to understand why. As per the household interviews in Sanjaynagar, provision of physical infrastructure was reported as most important. Better social standing and security of tenure came second and third as reasons for investment.

Other reasons stated for investment in housing included marriage in family, dignity of being able to invite relatives to come and stay and the better environment that a new house creates. 
Similarly, the residents of Khokhra highlighted that they would be interested in investing in housing if they were provided infrastructure facilities and land security. Though physical infrastructure is stated as the principal incentive for investment in housing stock, land security also has a role to play and it would be difficult to isolate the causes at this stage of the research.

\section{Land security}

In Sanjaynagar, a 'no eviction' lease of 10 years was provided from 1995. This started a flurry of housing upgradation activities. Now that the lease is coming to an end, residents have slowed down on investments until AMC processes an extension for another 10 years. Then, all the respondents would like to upgrade the roofs from tin to concrete with the possibility of building another floor.

Slum dwellers encroach on empty lands owned by the government or private owners. The non-slum citizens respond by demanding for their eviction out of sight and curbing new migrations to cities. However, with the pull factor of higher urban employment and push factor of lower agricultural incomes with the subdivision of land, it is impossible to stop migration. The governments should, therefore, develop strategies to assimilate this inevitable influx in terms of continuously making available serviced land together with security of tenure.

\section{Conclusions}

The study validates the technical approach and shows cent percent community satisfaction. It proves that physical infrastructure rapidly alleviates poverty with tangible improvements in health, education, disposable incomes and quality of life. The research shows that huge investment multipliers have been achieved as a result of infrastructure development and the partnerships. Factors such as social aspirations and land tenure have also helped. The key reported reason for community investments is the provision of individual facilities at low costs.

\section{Acknowledgements}

Special thanks to Himanshu Parikh whose concepts and efforts have been the inspiration of this work. The paper draws heavily on the author's MPhil dissertation 'An innovative approach to physical infrastructure as a means to overcoming poverty in developing countries'.

\section{References}

Ahmedabad Municipal Corporation (AMC) (2005) Slum Networking Programme - A Partnership Programme of Infrastructure and Social Development in Slums of Ahmedabad City, Submitted to Human Settlement Management Institute (HSMI).

Diacon, D. (1997) Slum Networking - An Innovative Approach to Urban Development, Building and Social Housing Foundation. 
Parikh, H. (1995) Slum Networking of Ahmedabad City, A Proposal for 'Slum Networking' of Ahmedabad City. For Ahmedabad Municipal Corporation, 1995.

Parikh, P. (2004) Development of Village Physical Infrastructure in Ghogha Region of Western India - Case study of 'Bapada Village.

Parikh, H. (1999) Slum Networking - An Alternate Way to Reach the Urban Poor, Using Slums to Save Cities, Ahmedabad.

Parikh, P. (2005) 'An innovative approach to physical infrastructure as a means to overcoming poverty in developing countries', MPhil Thesis submitted to Cambridge University, Cambridge.

Parikh, P. (2006) 'Impact of water and sanitation infrastructure on poverty alleviation in low income settlements', Draft first year PhD Thesis submitted to Cambridge University, Cambridge.

Robson, C. (1993) Real World Research, 2nd edition, Blackwell Publishing.

SAATH (1995) A Profile of Sanjaynagar, Survey of Sanjaynagar.

SHARDA Trust and SAATH (1999) Sanjay Nagar, A Postscript.

Siegel, S. (1956) Non Parametric Statistics for the Behavioural Sciences, MrGraw-Hill Series in Psychology.

SnehPrayas (2004) Household Surveys in Sanjaynagar for Education and Income Levels.

Tripathi, D. (1998) Alliance for Change - A Slum Upgrading Experiment in Ahmedabad, Tata McGraw-Hill.

Tripathi, D. (1999) Slum Networking in Ahmedabad: The Sanjay Nagar Pilot Project, Working Paper No. 101, Available at: http://www.ucl.ac.uk/dpu/publications/working\%20papers\% 20pdf/wp101.pdf. Accessed on 3 March 2006.

Tripathi, D. and Jumani, J. (2001) Change After Alliance Sequel to Alliance for Change, Tata McGraw Hill.

UNICEF/WHO (2004) Meeting the MDG Drinking Water and Sanitation Target, A Mid Term Assessment of Progress.

World Bank (WB) (2004) World Development Report, Making Services Work for Poor People, New York: Oxford University Press. 